\title{
Phenosafranin-Based Colorimetric-Sensing Platform for Nitrite Detection Enabled by Griess Assay
}

\author{
Jingzhou Hou ${ }^{1,2,+}$, Huixiang $\mathrm{Wu}^{3,4,+}$, Xin Shen ${ }^{3}$, Chao Zhang ${ }^{2}$, Changjun Hou ${ }^{3}$, Qiang He ${ }^{1, *}$ \\ and Danqun Huo ${ }^{3,5, *}$ \\ 1 Key Laboratory of Eco-Environment of Three Gorges Region of Ministry of Education, College of \\ Environment and Ecology, Chongqing University, Chongqing 400045, China; houjz@cqu.edu.cn \\ 2 Solid-state Fermentation Resource Utilization Key Laboratory of Sichuan Province, Yibin University, \\ Yibin 644000, China; 2001106001@yibinu.edu.cn \\ 3 Key Laboratory for Biorheological Science and Technology of Ministry of Education, State and Local Joint \\ Engineering Laboratory for Vascular Implants, Bioengineering College of Chongqing University, \\ Chongqing 400044, China; cce.whx@gzhu.edu.cn (H.W.); 20151913064@cqu.edu.cn (X.S.); \\ houcj@cqu.edu.cn (C.H.) \\ 4 School of Chemistry and Chemical Engineering, Guangzhou Key Laboratory of Clean Energy and Materials, \\ Guangzhou University, Guangzhou 510006, China \\ 5 Chongqing Key Laboratory of Bio-perception \& Intelligent Information Processing, School of \\ Microelectronics and Communication Engineering, Chongqing University, Chongqing 400044, China \\ * Correspondence: heq0980@cqu.edu.cn (Q.H.); huodq@cqu.edu.cn (D.H.); Tel.: +86-023-6512-7226 (Q.H.); \\ +86-023-6511-2673 (D.H.) \\ + These two authors made equal contributions to this work.
}

Received: 11 February 2020; Accepted: 29 February 2020; Published: 9 March 2020

\begin{abstract}
A facile and effective colorimetric-sensing platform based on the diazotization of phenosafranin for the detection of $\mathrm{NO}_{2}^{-}$under acidic conditions using the Griess assay is presented. Diazotization of commercial phenosafranin produces a color change from purplish to blue, which enables colorimetric quantitative detection of $\mathrm{NO}_{2}^{-}$. Optimal detection conditions were obtained at a phenosafranin concentration of $0.25 \mathrm{mM}, \mathrm{HCl}$ concentration of $0.4 \mathrm{M}$, and reaction time of $20 \mathrm{~min}$. Under the optimized detection conditions, an excellent linearity range from 0 to $20 \mu \mathrm{M}$ was obtained with a detection limit of $0.22 \mu \mathrm{M}$. Favorable reproducibility and selectivity of the colorimetric sensing platform toward $\mathrm{NO}_{2}^{-}$were also verified. In addition, testing spiked ham sausage, bacon, and sprouts samples demonstrated its excellent practicability. The presented colorimetric sensing platform is a promising candidate for the detection of $\mathrm{NO}_{2}^{-}$in real applications.
\end{abstract}

Keywords: Griess assay; colorimetric; nitrite; phenosafranin

\section{Introduction}

As one of the most important inorganic salt anions, nitrite $\left(\mathrm{NO}_{2}^{-}\right)$plays significant roles in the fields of food, organic synthesis, pharmaceuticals, dyes, and agrochemicals [1-5]. However, the widespread use of nitrite poses a great threat to the environment due to its persistence in the soil and water $[6,7]$. In particular, in order to inhibit the propagation of toxic microorganisms in food and improve the color and flavor of meat products, nitrite has also been heavily used as an additive [8-12]. Extensive intake of nitrite can result in dysfunction of hemoglobin, digestive system cancer, and some other diseases [13-17]. In regards to the these problems, World Health Organization (WHO) and U.S. Environmental Protection Agency (EPA) set maximum contaminant levels (MCL) of nitrite in drinking water to $3.0 \mathrm{mg} / \mathrm{L}(65.1 \mu \mathrm{M})$ and $1.0 \mathrm{mg} / \mathrm{L}(21.7 \mu \mathrm{M})$, respectively [18]. Therefore, detection of nitrite is of great importance for environmental protection and food safety. 
Currently, numerous detection technologies have been developed for the nitrite analysis. For example, high performance liquid chromatography (HPLC) [19,20], ion chromatography (IC) [21,22], gas chromatography-mass spectrometry (GC-MS) [23,24], and other sensing platform [25] are widely employed for the detection of nitrite. Despite accuracy and sensitivity, the large-scaled equipment needed, complex samples pretreatment, and requirement of skilled personnel handicap their in-field applications. To address these issues, electrochemical sensors based on various nano-materials were fabricated [26-28]. Yet, the vulnerability of the electrode (ease of being poisoned) may influence the sensitivity and precision of detection. The reproducibility and selectivity could pose large challenges for real samples analysis based on electrochemical sensors [29,30]. Thus, the development of a robust and simple sensing platform for nitrite detection is urgently needed.

The colorimetric sensor is being examined by scientists and engineers in the field of nitrite discrimination due to its speed and ability to be visualized by naked eyes [31-35]. Among them, the catalytic spectrophotometric method was extensively investigated based on the reaction between an oxidizing agent (potassium bromate, potassium chlorate, potassium permanganate, and hydrogen peroxide) and some organic dyes in the presence of nitrite, which leads to the color change of dyes and quantitative detection of nitrite [36,37]. However, the time-consuming catalytic spectrophotometric method and the ease of disturbance by $\mathrm{SO}_{3}^{2-}, \mathrm{Br}^{-}$, and $\mathrm{I}^{-}$hinder their widespread use in real application [38]. The Griess assay, as one of the most common alternatives to the colorimetric detection of nitrite, involves a diazo-coupling procedure under acidic conditions in the presence of nitrite and $-\mathrm{NH}_{2}$ on a certain chromophore, by which the color of sensing system changes and subsequently nitrite detection is achieved [18,39]. For example, some reported a spectrophotometric sensor based on diazotization of p-nitrophenol (Griess assay) to quantitatively detect nitrite [40,41]. Although a satisfactory detection goal can be obtained using a UV-visible spectrometer, the relatively small conjugation degree of the diazonium salt of p-nitrophenol (absorbance at 400 to $500 \mathrm{~nm}$ ) is hard to visualize by the naked eye. Recently, Noor et al. [42] presented a new optosensor for visual quantitation of nitrite by physically immobilizing safranine $\mathrm{O}(\mathrm{SO})$ reagent onto a self-adhesive poly(n-butyl acrylate) (poly(nBA)) microspheres matrix. The large conjugate structure of SO (purplish) was diazotized through the Griess assay and formed a blue diazonium salt compound, which produces an obvious color change from purplish to blue and subsequently can be easily identified using the naked eye. The possible incomplete diazotization reaction resulted in a relatively high linear nitrite concentration ranging from 10 to $100 \mathrm{ppm}(0.22$ to $2.17 \mathrm{mM})$ in the solid phase, which does not meet the requirements set by the WHO $(65.22 \mu \mathrm{M})$ and EPA $(21.74 \mu \mathrm{M})[43]$.

To improve the practicality of the sensing platform for nitrite detection in the real world, we present a simple and effective colorimetric sensing platform based on the Griess assay. As shown in Figure 1, commercially cost-efficient phenosafranin (serving as the acting site and signal reporter) with large conjugated structure (purple) can be diazotized to form a blue diazonium salt (DOS) by nitrite under acidic conditions in the presence of nitrite in aqueous solution. Thus, qualitative and quantitative detection of nitrite was achieved according to the changes in absorbance of the UV-visible spectrum. In addition, the sensing platform was able to detect nitrite spiked into ham sausage, bacon, and sprouts with remarkable recovery. The results demonstrated that the sensing platform as presented displays excellent sensitivity and is robust against disturbance, and is a promising candidate for nitrite analysis in real samples.

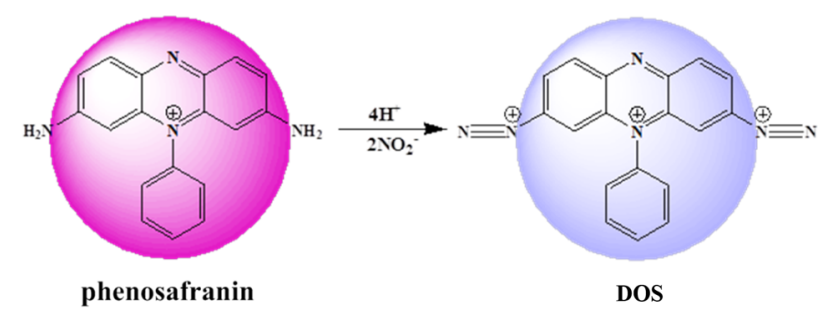

Figure 1. Scheme of proposed sensing platform. 


\section{Experiment}

\subsection{Reagents and Chemicals}

Phenosafranin (PS, 80\%) and $\mathrm{NaHSO}_{3}$ were purchased from Aladdin Chemistry (Shanghai, China). $\mathrm{NaHCO}_{3}$ was obtained from Chongqing Inorganic Chemical Reagent Plant. Disodium hydrogen phosphate $\left(\mathrm{Na}_{2} \mathrm{HPO}_{4}\right)$ and sodium hydroxide $(\mathrm{NaOH})$ were bought from Tianjin Chemical Reagent Co. Ltd. (Tianjin, China). A standard stock solution of $\mathrm{NO}_{2}^{-}$was prepared using $\mathrm{NaNO}_{2}$ with ultrapure water. Other stock solutions of anions at $15 \mathrm{mM}$ were prepared in ultrapure water with the corresponding salts with different anions of $\mathrm{NaHCO}_{3}, \mathrm{Na}_{2} \mathrm{SO}_{4}, \mathrm{Na}_{2} \mathrm{SO}_{3}, \mathrm{Na}_{2} \mathrm{~S}_{2} \mathrm{O}_{3} \cdot 5 \mathrm{H}_{2} \mathrm{O}$, $\mathrm{Na}_{2} \mathrm{~S}_{2} \mathrm{O}_{5}, \mathrm{Na}_{2} \mathrm{CO}_{3}, \mathrm{Na}_{3} \mathrm{PO}_{4} \cdot 12 \mathrm{H}_{2} \mathrm{O}, \mathrm{Na}_{2} \mathrm{HPO}_{4} \cdot 12 \mathrm{H}_{2} \mathrm{O}, \mathrm{NaH}_{2} \mathrm{PO}_{4}, \mathrm{CH}_{3} \mathrm{COONa}, \mathrm{C}_{6} \mathrm{H}_{5} \mathrm{O}_{7} \mathrm{Na}_{3} \cdot 2 \mathrm{H}_{2} \mathrm{O}$, $\mathrm{NaF}, \mathrm{NaCl}, \mathrm{NaBr}, \mathrm{NaI}, \mathrm{NaNO}_{3}, \mathrm{NH}_{4} \mathrm{NO}_{3}, \mathrm{NH}_{4} \mathrm{Cl}, \mathrm{KCl}, \mathrm{MgCl}_{2}, \mathrm{CuCl}_{2} \cdot 2 \mathrm{H}_{2} \mathrm{O}, \mathrm{MnCl}_{2} \cdot 4 \mathrm{H}_{2} \mathrm{O}, \mathrm{KSCN}$, $\mathrm{FeCl}_{3}$, and $\mathrm{FeCl}_{2} \cdot 4 \mathrm{H}_{2} \mathrm{O}$. All the above-mentioned chemicals were purchased from Chengdu Kelong Chemical Reagent Factory (Chengdu, China) except where indicated. All the above-mentioned reagents were of analytical purity unless otherwise stated. All aqueous solutions were prepared with deionized (DI) water $(18.25 \mathrm{M} \Omega \mathrm{cm})$ from a Millipore water system.

\subsection{Instruments}

The UV-Vis absorption spectra obtained were recorded by a TU-1901 double-beam UV-vis spectrophotometer (Peking General Instrument Co. Ltd. Beijing, China). Fourier-transform infrared spectroscopy (FT-IR) with Spectrum GX Infrared and Microscopy System (PerkinElmer, USA) were used to confirm the chemical structure change of phenosafranin.

\subsection{Preparation of Stock Solutions}

To form $1 \mathrm{M}$ aqueous stock solution for further use, $6.90 \mathrm{~g}$ of $\mathrm{NaNO}_{2}$ was dissolved in $100 \mathrm{~mL}$ deionized water. We prepared $1 \mathrm{M} \mathrm{HCl}$ aqueous solution by diluting $9 \mathrm{~mL}$ concentrated hydrochloric acid $(36 \%-39 \%)$ into $100 \mathrm{~mL}$ deionized water. All the inorganic salts aqueous solutions were obtained by diluting them into $100 \mathrm{~mL}$ deionized water to form $0.1 \mu \mathrm{M}$ stock solutions. All these aqueous solutions with certain concentrations were acquired by diluting corresponding stock solutions.

\subsection{Preparation of Real Samples}

Sprouts, bacon, and ham sausages bought from the local supermarket were selected as real samples for modeling the real world application of the proposed sensing platform. Pretreatment of these samples was performed according to the GB 5009.33-2016 (determination of nitrite and nitrate in food). Five grams of sample (sprouts, bacon, and ham sausage) was cut up and put into a $250 \mathrm{~mL}$ conical flask loaded with $10 \mathrm{~mL}$ deionized water to form a homogenate. After that, $12.5 \mathrm{~mL}$ saturated borax solution $(50 \mathrm{~g} / \mathrm{L})$ and $150 \mathrm{~mL}$ hot deionized water $\left(70{ }^{\circ} \mathrm{C}\right)$ were added into the conical flask and incubated boiling water for $15 \mathrm{~min}$. Then, the conical flask was taken out and cooled to room temperature. The extracting solution was transferred to $200 \mathrm{~mL}$ volumetric flask and added with $5 \mathrm{~mL}$ potassium ferricyanide aqueous solution $(106 \mathrm{~g} / \mathrm{L})$. After shaking up, $5 \mathrm{~mL}$ zinc acetate solution $(220 \mathrm{~g} / \mathrm{L})$ was added to precipitate the protein. Subsequently, deionized water was added into the volumetric flask to a total volume of $200 \mathrm{~mL}$ and allowed to stand for $30 \mathrm{~min}$. Residuals were removed by filtering the stock solution was acquired. Finally, real samples were obtained after stock solution spiking with various concentrations of $\mathrm{NO}_{2}^{-}$.

\subsection{Measurement Procedure}

The analytical performance of phenosafranin toward $\mathrm{NO}_{2}^{-}$was investigated at room temperature. Briefly, the phenosafranin solution $(0.5 \mathrm{~mL}, 0.25 \mathrm{mM})$ was mixed with $\mathrm{HCl}$ aqueous solution $(2 \mathrm{~mL}$, $0.4 \mathrm{M}$ ) and loaded into a $5 \mathrm{~mL}$ centrifuge tube, followed by adding $1 \mathrm{~mL} \mathrm{NO}_{2}^{-}$in certain concentrations and incubating for $15 \mathrm{~min}$. Finally, the UV-visible spectra of the mixture were recorded. 


\section{Results and Discussion}

\subsection{Sensing Mechanism}

The mechanism of the phenosafranin-based colorimetric-sensing platform is shown in Figures 1 and 2. $\mathrm{HCl}$ was employed since the Griess assay occurs under acidic conditions. As shown in Figure 2, the UV-visible absorbance spectrum of phenosafranin was dominated by a single intense peak at $538 \mathrm{~nm}$. No obvious change was observed for absorbance spectra of phenosafranin after incubation with $\mathrm{HCl}$, indicating no influence of $\mathrm{HCl}$ on the color change of phenosafranin. Upon addition of $\mathrm{NO}_{2}^{-}$at a concentration of $14 \mu \mathrm{M}$ into phenosafranin solution with the presence of $\mathrm{HCl}$, the strong absorbance peak at $538 \mathrm{~nm}$ receded and broadened, accompanied by a slight bathochromic shift (Figure 2), which can be ascribed to the diazotization of phenosafranin in agreement with a previous report [42]. As displayed in Figure 1, diazotization of $-\mathrm{NH}_{2}$ increases the conjugation degree of phenosafranin, resulting in the bathochromic shift of the absorbance peak. The color change of sensing system from red to blue can be clearly verified by the photo images in the inset of Figure 2. In order to demonstrate the chemical structure change, the DOS sample was first obtained by complete reaction between high concentration phenosafranin aqueous solutions with excess sodium nitrite under acidic conditions. Figure 3 shows the FT-IR spectra of phenosafranin and DOS in the wavenumber ranging from 2000 to $4000 \mathrm{~cm}^{-1}$. Two well-defined peaks at 3320.0 and $3185.0 \mathrm{~cm}^{-1}$ of phenosafranin are attributed to stretching vibration of amino group. After complete reaction with excessive $\mathrm{NO}_{2}^{-}$, the stretching vibration of amino group disappeared, suggesting the formation of diazonium salts DOS. Thus, colorimetric detection of $\mathrm{NO}_{2}^{-}$based on phenosafranin under acidic conditions through the Griess assay could be achieved.

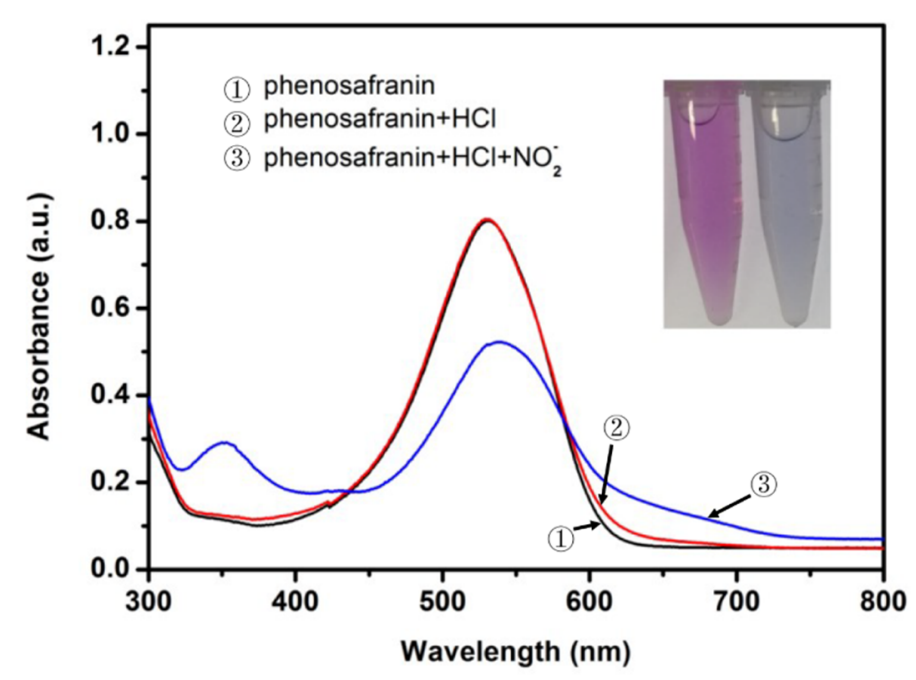

Figure 2. UV-visible spectra of phenosafranin $(0.25 \mathrm{mM})$ before and after incubation with $\mathrm{NO}_{2}^{-}(10 \mu \mathrm{M})$ under acidic condition $(\mathrm{HCl}$ of $0.4 \mathrm{M}$ ) (inset: corresponding photo image with (right) and without (left) $\mathrm{NO}_{2}^{-}$). 


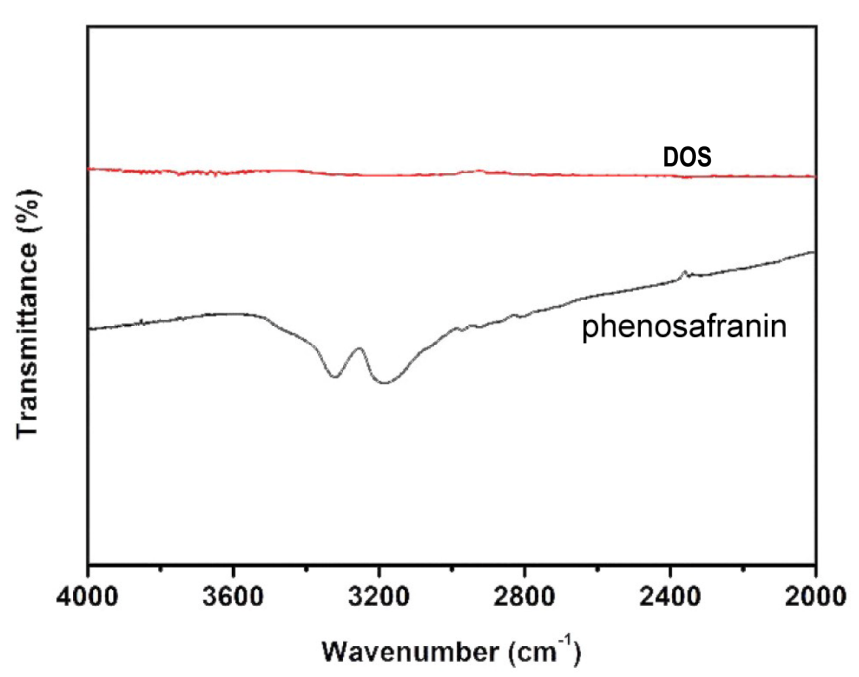

Figure 3. Fourier-transform infrared spectroscopy (FT-IR) spectra of phenosafranin and DOS.

\subsection{Optimization of Detection Conditions}

In order to obtain an improved colorimetric response, the influence of concentrations of phenosafranin and $\mathrm{HCl}$ and incubation time were studied. As a sensing element and signal producer, a higher concentration of phenosafranin enables a more efficient diazotization reaction. However, quantitative detection is affected by the exorbitant concentration of phenosafranin due to the deviation from Lambert's law. Additionally, a deep background disturbance influences the judgment on the color change of the sensing platform, extremely in the case of trace $\mathrm{NO}_{2}^{-}$sensing. Therefore, appropriate concentration is important for the fabricated sensing platform. Figure $4 \mathrm{~A}$ displays the absorbance spectra of phenosafranin at five concentrations. Taking these considerations into account, $0.25 \mathrm{mM}$ phenosafranin was used for further studies. After optimization of phenosafranin concentration, the effect of concentration of $\mathrm{HCl}$ was also investigated. As shown in Figure $4 \mathrm{~B}$, the changes in the absorbance of phenosafranin $(\triangle \mathrm{A})$ at $532 \mathrm{~nm}$ increased with increasing $\mathrm{HCl}$ addition until it reached a maximum at a $\mathrm{HCl}$ concentration of $0.4 \mathrm{M}$ and $\mathrm{NO}_{2}^{-}$concentration of $14 \mu \mathrm{M}$, suggesting that $\mathrm{HCl}$ facilitates the diazotization of phenosafranin. At high $\mathrm{HCl}$ concentration $(>0.4 \mathrm{M}), \Delta \mathrm{A}$ decreased gradually with the increase in concentration of $\mathrm{HCl}$, which may be contributed by the protonation of amidogen, being detrimental to diazotization [44]. Thus, we selected the $\mathrm{HCl}$ concentration of $0.4 \mathrm{M}$ as optimal for conducting subsequent studies. Additionally, the influence of incubation time on $\mathrm{NO}_{2}^{-}$detection even with large concentration $(20 \mu \mathrm{M}$, to ensure the complete reaction time we can obtain) was researched and the test results are presented in Figure 4C. After a 10-minute incubation, an intense $\Delta \mathrm{A}$ was obtained. After $20 \mathrm{~min}$ of reaction time, the $\Delta \mathrm{A}$ leveled off, indicating that the reaction reached saturation. Typically, the reaction time of $20 \mathrm{~min}$ was chosen as the optimal time for further tests. Generally, we used the optimized phenosafranin concentration of $0.25 \mathrm{mM}, \mathrm{HCl}$ concentration of $0.4 \mathrm{M}$, and reaction time of 20 as favorable detection conditions for the investigation of the analytical performance of the sensing platform for $\mathrm{NO}_{2}^{-}$. 

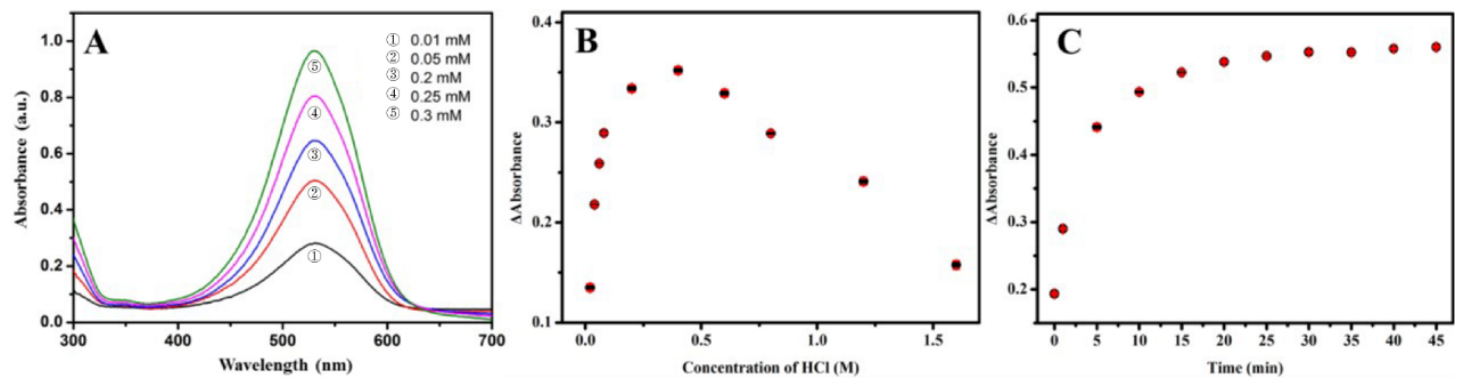

Figure 4. Optimization of concentrations of (A) phenosafranin $(0.01,0.05,0.2,0.25,0.3 \mathrm{mM}),(\mathbf{B}) \mathrm{HCl}$ $(0.025,0.05,0.075,0.1,0.2,0.4,0.6,0.8,1.2,1.6 \mathrm{M})$, and $(\mathrm{C})$ reaction time $(0,1,5,10,15,20,25,30,35,40$, $45 \mathrm{~min})$.

\subsection{The Sensitivity of Colorimetric Sensing Platform}

Under optimized detection condition, the sensitivity of the colorimetric sensor for $\mathrm{NO}_{2}^{-}$was investigated and the test results are displayed in Figure 5. The UV-visible spectra, in the range from 300 to $750 \mathrm{~nm}$ of $0.25 \mathrm{mM}$ phenosafranin in the presence of $\mathrm{NO}_{2}^{-}$with various concentrations, are recorded in Figure 5A. Well-defined UV-visible absorbance peaks were obtained after incubation with $\mathrm{NO}_{2}^{-}$ in different concentrations. The absorbance peaks intensities decreased at $532 \mathrm{~nm}$ gradually with increasing concentrations ranging from 0 to $100 \mu \mathrm{M}$, accompanied by gradually increasing bathochromic shift. New stepped-up peaks at $350 \mathrm{~nm}$ arose with increasing $\mathrm{NO}_{2}^{-}$concentrations. Figure $5 \mathrm{~B}$ shows the $\Delta \mathrm{A}$ at $532 \mathrm{~nm}$ with the addition of different concentrations of $\mathrm{NO}_{2}^{-}$. When increasing $\mathrm{NO}_{2}^{-}$ concentrations, $\triangle \mathrm{A}$ increased accordingly. A well-defined linear relationship $\left(\mathrm{R}^{2}=0.9977\right)$ between $\Delta \mathrm{A}$ with $\mathrm{NO}_{2}^{-}$ranging from 0 to $20 \mu \mathrm{M}$ was obtained. The detection limit was calculated to be $0.22 \mu \mathrm{M}(3 \mathrm{~S} / \mathrm{N})$, which is much lower than the MCL of nitrite in drinking water set by the EPA and the WHO. Notably, satisfactory sensitivity and linear relationship range were acquired compared with the previously reported colorimetric sensing platform listed in Table 1, which are attributed to the large conjugated structure of phenosafranin and its highly reactive diazotization reaction. The low cost and ease of operation of this colorimetric sensing platform enable its widespread use. The test results demonstrated the potential feasibility of the sensing platform for the quantitative detection of $\mathrm{NO}_{2}^{-}$ within the requirements given by the EPA and WHO.
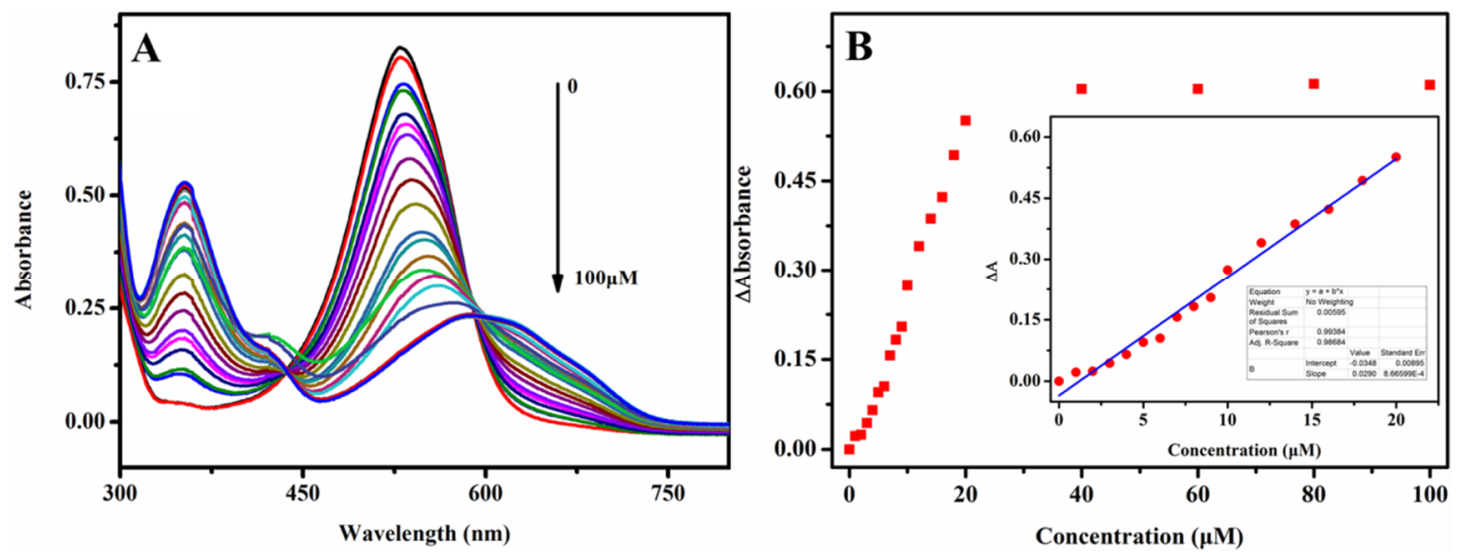

Figure 5. (A) UV spectra of phenosafranin $(0.25 \mathrm{mM})$ at $\mathrm{HCl}$ concentration of $0.4 \mathrm{M}$ versus $\mathrm{NO}_{2}^{-}$with various concentrations from 0 to $100 \mu \mathrm{M}$ and (B) corresponding $\Delta \mathrm{A}$ at $532 \mathrm{~nm}$ of the sensing system at respective $\mathrm{NO}_{2}^{-}$concentrations; (inset $\mathrm{B}$ : linear relationship between $\Delta \mathrm{A}$ and $\mathrm{NO}_{2}^{-}$concentrations ranging from 0 to $20 \mu \mathrm{M})$. 
Table 1. Comparison of the analytical performance of previously reported colorimetric sensors with this work.

\begin{tabular}{cccc}
\hline Reagents & Linearity Ranges $(\mu \mathbf{M})$ & Detection Limits $(\mu \mathbf{M})$ & Reference \\
\hline azo-BODIPY & $0-50$ & 0.5 & {$[8]$} \\
Ruthenium complexes & $1-840$ & 0.39 & {$[32]$} \\
4-ATP/AuNPs & $1-25$ & 1 & {$[33]$} \\
Griess reagent & $1.6-21.74$ & 0.86 & {$[34]$} \\
safranine O (SO) & $10-100 \mathrm{ppm}$ & $3 \mathrm{ppm}$ & {$[41]$} \\
phenosafranin & $0.1-20$ & 0.22 & this work \\
\hline
\end{tabular}

\subsection{Interferences Study}

We conducted an interferences study to verify the selectivity of the colorimetric sensing platform. We selected 27 potential co-existing organic salts or alkali as interference chemicals to be tested. As shown in Figure $6, \Delta \mathrm{A}$ at $532 \mathrm{~nm}$ of the sensing platform after reaction with different substances (350 $\mu \mathrm{M} \mathrm{Na}_{2} \mathrm{SO}_{4}, \mathrm{NaHSO}_{3}, \mathrm{Na}_{2} \mathrm{~S}_{2} \mathrm{O}_{3}, \mathrm{Na}_{2} \mathrm{SO}_{3}, \mathrm{Na}_{2} \mathrm{~S}_{2} \mathrm{O}_{5}, \mathrm{Na}_{2} \mathrm{CO}_{3}, \mathrm{NaHCO}_{3}, \mathrm{Na}_{3} \mathrm{PO}_{4}, \mathrm{Na}_{2} \mathrm{HPO}_{4}$, $\mathrm{NaH}_{2} \mathrm{PO}_{4}, \mathrm{CH}_{3} \mathrm{COON}_{\mathrm{a}}, \mathrm{C}_{6} \mathrm{H}_{5} \mathrm{O}_{7} \mathrm{Na}_{3}, \mathrm{NaOH}, \mathrm{NaF}, \mathrm{NaCl}, \mathrm{NaBr}, \mathrm{NaI}, \mathrm{NaNO}_{3}, \mathrm{NH}_{4} \mathrm{Cl}_{2} \mathrm{NH}_{4} \mathrm{NO}_{3}, \mathrm{KCl}$, $\mathrm{KSCN}, \mathrm{CuCl}_{2}, \mathrm{MgCl}_{2}, \mathrm{FeCl}_{2}, \mathrm{FeCl}_{3}$, and $\mathrm{MnCl}_{2}$ ) under optimal conditions were recorded, suggesting little influence on the sensing platform from these interferences. In contrast, $\triangle \mathrm{A}$ (absorbance change) at $532 \mathrm{~nm}$ of the as-presented sensing platform after incubation with $35 \mu \mathrm{M}$ of $\mathrm{NaNO}_{2}$ under the same detection conditions significantly increased, indicating a good selectivity of this sensing platform toward $\mathrm{NO}_{2}^{-}$. The selectivity of the sensing platform was assigned to the diazotization reaction of phenosafranin with $\mathrm{NO}_{2}^{-}$. The results indicated that the colorimetric sensing platform presented here has a good anti-disturbance ability.

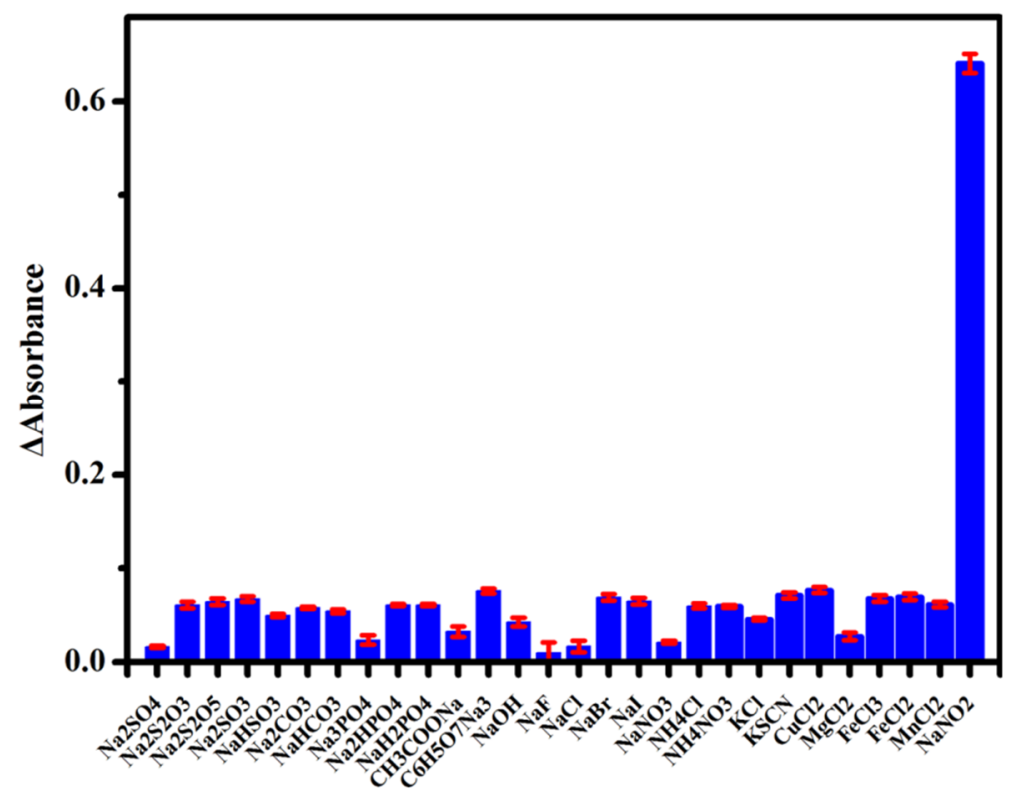

Figure 6. $\Delta \mathrm{A}$ at $532 \mathrm{~nm}$ of the sensing platform for $\mathrm{NaNO}_{2}(35 \mu \mathrm{M})$ and other analytes $(350 \mu \mathrm{M})$.

\subsection{Reproducibility Study}

To evaluate the stability, we recorded $\Delta \mathrm{A}$ at $532 \mathrm{~nm}$ for the sensing platform upon incubation with $35 \mu \mathrm{M} \mathrm{NaNO}{ }_{2}$ under the optimized detection conditions. Ten batches with six replicates for one batch were tested and the results are shown in Figure 7. An excellent reproducibility (relative standard deviation $(\mathrm{RSD})=1.59 \%$ ) of the colorimetric sensing platform was obtained. 


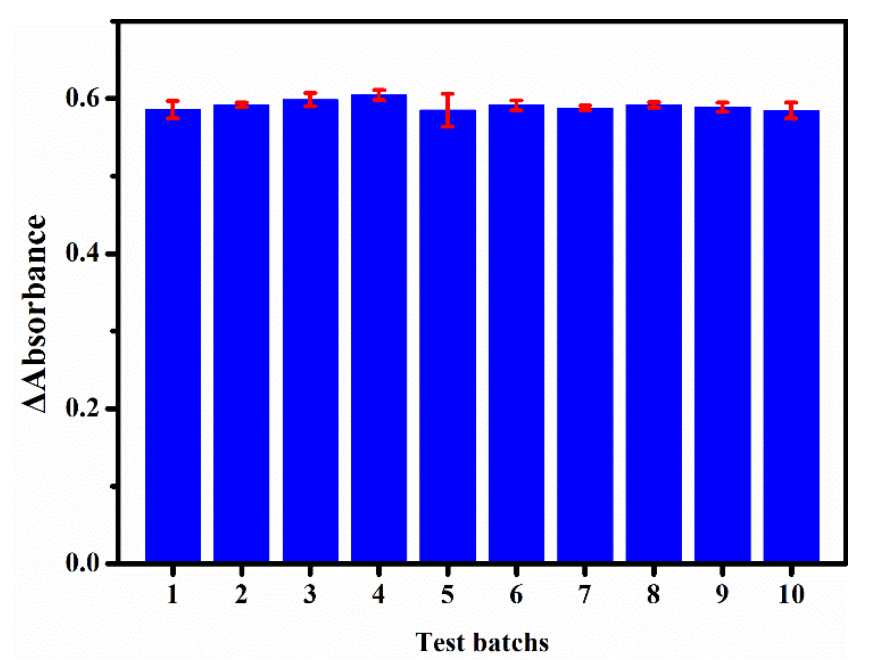

Figure 7. $\Delta \mathrm{A}$ at $532 \mathrm{~nm}$ for the sensing platform for 10 batches of tests $\left(35 \mu \mathrm{M}\right.$ of $\left.\mathrm{NaNO}_{2}\right)$ at different times.

\subsection{The Practicability of the Colorimetric Sensing Platform}

Various concentrations of $\mathrm{NO}_{2}^{-}$spiked ham sausage, bacon, and sprouts samples (real sample pretreatment procedure was described in Preparation of real samples) were tested to evaluate the practicability of the colorimetric sensing platform. The $\Delta \mathrm{A}$ at $532 \mathrm{~nm}$ of ham sausage, bacon, and sprouts samples spiked with $\mathrm{NO}_{2}^{-}$were recoded to calculate the recoveries (Table 2). The detection results matched well with the accurate concentration for nearly all cases spiked with 0,10 , and $20 \mu \mathrm{M}$ of $\mathrm{NO}_{2}^{-}$, demonstrating the good practicability of the colorimetric sensing platform. The recoveries acquired were calculated to range from $94.63 \%$ to $109.94 \%$, with favorable reproducibility (RSD $<2 \%$ ). These results suggested that the colorimetric sensing platform displays the potential for trace $\mathrm{NO}_{2}^{-}$detection in real applications.

Table 2. Detection of $\mathrm{NO}_{2}^{-}$in spiked ham sausage, bacon, and sprouts samples.

\begin{tabular}{ccccc}
\hline Samples & Added $(\boldsymbol{\mu M})$ & Found $(\boldsymbol{\mu M})$ & RSD $(\%)$ & Recoveries $(\mathbf{\%})$ \\
\hline \multirow{3}{*}{ ham sausage } & 0 & 1.68 & $/$ & $/$ \\
& 10 & 12.6 & 1.5 & 108.97 \\
& 20 & 20.6 & 1.3 & 94.63 \\
\hline \multirow{3}{*}{ bacon } & 0 & 1.56 & $/$ & $/$ \\
& 10 & 11.9 & 1.4 & 103.74 \\
sprouts & 20 & 1.93 & 1.2 & $/$ \\
& 0 & 12.9 & 1.8 & 109.94 \\
& 10 & 21.1 & 1.3 & 95.91 \\
\hline
\end{tabular}

\section{Conclusions}

We presented a simple and effective colorimetric sensing platform based on the diazotization of phenosafranin for the detection of $\mathrm{NO}_{2}^{-}$under acidic conditions using the Griess assay. Commercial phenosafranin served as both acting site and signal producer. The color of phenosafranin changed from purplish to blue upon addition of $\mathrm{NO}_{2}^{-}$, enabling colorimetric sensing to achieve quantitative detection of $\mathrm{NO}_{2}^{-}$. A satisfactory sensitivity and favorable linearity were obtained under the optimal detection conditions. Interferences and reproducibility studies were conducted verify the selectivity and stability of the sensing platform. The testing of spiked real samples (ham sausage, bacon, and sprouts) confirmed its excellent practicability. All the results suggested the presented colorimetric sensing platform is a promising strategy for $\mathrm{NO}_{2}^{-}$analysis in real applications. 
Author Contributions: J.H. and H.W. consulted the literature, conducted the experiments, charted production, and initiated the writing of the manuscript; these two authors made equal contributions to this work. X.S. and C.Z. discussed the results and revised the manuscript. Q.H. and D.H. conceived and developed the data analysis methods. C.H. took part in data analysis and revision of the manuscript. D.H. managed the project and also finalized the manuscript. All authors have read and agreed to the published version of the manuscript.

Funding: This work was supported by the Fundamental Research Funds for the Central University (2018CDYJSY0055), Solid-State Fermentation Resource Utilization Key Laboratory of Sichuan Province (No. 2018GTJ010), the National Natural Science Foundation of China Chongqing Science and Technology Commission (CSTC2018jcyjAX0062), Brew Microorganisms Technology and Application of Key Laboratory Project in Sichuan Province (No. NJ2018-01), Chongqing Graduate Tutor Team Construction Project, Analytical and Testing Center of Chongqing University for FT-IR characterization and the sharing fund of Chongqing University's large equipment.

Conflicts of Interest: The authors declare no conflicts of interest.

\section{References}

1. World Health Organization. The Selection and Use of Essential Medicines: World Health Organization Technical Report Series; World Health Organization: Geneva, Switzerland, 2011.

2. Gomes, A.; Fernandes, E.; Lima, J.L. Use of fluorescence probes for detection of reactive nitrogen species: A review. J. Fluoresc. 2006, 16, 119-139. [CrossRef]

3. Ghosh, A.; Das, P.; Saha, S.; Banerjee, T.; Bhatt, H.B.; Das, A. Diamine derivative of a ruthenium (II)-polypyridyl complex for chemodosimetric detection of nitrite ion in aqueous solution. Inorg. Chim. Acta 2011, 372, 115-119. [CrossRef]

4. Møller, J.K.; Skibsted, L.H. Nitric oxide and myoglobins. Chem. Rev. 2002, 102, 1167-1178. [CrossRef] [PubMed]

5. Carlsen, C.U.; Møller, J.K.; Skibsted, L.H. Heme-iron in lipid oxidation. Coord. Chem. Rev. 2005, 249, $485-498$. [CrossRef]

6. Chung, J.-C.; Chou, S.-S.; Hwang, D.-F. Changes in nitrate and nitrite content of four vegetables during storage at refrigerated and ambient temperatures. Food Addit. Contam. 2004, 21, 317-322. [CrossRef] [PubMed]

7. Li, H.-q.; Han, H.-j. Nitrite accumulation performance of aerobic MBBR treating Lurgi coal gasification waste water by adjusting pollutant load and DO concentration. Environ. Technol. 2015, 36, 3210-3220. [CrossRef]

8. Adarsh, N.; Shanmugasundaram, M.; Ramaiah, D. Efficient reaction based colorimetric probe for sensitive detection, quantification, and on-site analysis of nitrite ions in natural water resources. Anal. Chem. 2013, 85, 10008-10012. [CrossRef]

9. Sebranek, J.G.; Bacus, J.N. Cured meat products without direct addition of nitrate or nitrite: What are the issues? Meat Sci. 2007, 77, 136-147. [CrossRef]

10. Yetim, H.; Kayacier, A.; Kesmen, Z.; Sagdic, O. The effects of nitrite on the survival of Clostridium sporogenes and the autoxidation properties of the Kavurma. Meat Sci. 2006, 72, 206-210. [CrossRef]

11. Salama, M.F.; Abbas, A.; Darweish, M.M.; El-Hawwary, A.A.; Al-Gayyar, M.M. Hepatoprotective effects of cod liver oil against sodium nitrite toxicity in rats. Pharm. Biol. 2013, 51, 1435-1443. [CrossRef]

12. Froehlich, D.A.; Gullett, E.; Usborne, W. Effect of nitrite and salt on the color, flavor and overall acceptability of ham. J. Food Sci. 1983, 48, 152-154. [CrossRef]

13. Jiao, S.; Jin, J.; Wang, L. One-pot preparation of Au-RGO/PDDA nanocomposites and their application for nitrite sensing. Sens. Actuators B Chem. 2015, 208, 36-42. [CrossRef]

14. Xiao, N.; Yu, C. Rapid-response and highly sensitive noncross-linking colorimetric nitrite sensor using 4-aminothiophenol modified gold nanorods. Anal. Chem. 2010, 82, 3659-3663. [CrossRef] [PubMed]

15. Chan, T.Y. Food-borne nitrates and nitrites as a cause of methemoglobinemia. Southeast Asian J. Trop. Med. Public Health 1996, 27, 189-192. [PubMed]

16. Li, L.; Wang, P.; Xu, X.; Zhou, G. Influence of Various Cooking Methods on the Concentrations of Volatile N-Nitrosamines and Biogenic Amines in Dry-Cured Sausages. J. Food Sci. 2012, 77, C560-C565. [CrossRef] [PubMed]

17. Brender, J.D.; Olive, J.M.; Felkner, M.; Suarez, L.; Marckwardt, W.; Hendricks, K.A. Dietary nitrites and nitrates, nitrosatable drugs, and neural tube defects. Epidemiology 2004, 15, 330-336. [CrossRef] 
18. Daniel, W.L.; Han, M.S.; Lee, J.-S.; Mirkin, C.A. Colorimetric nitrite and nitrate detection with gold nanoparticle probes and kinetic end points. J. Am. Chem. Soc. 2009, 131, 6362-6363. [CrossRef]

19. Li, H.; Meininger, C.J.; Wu, G. Rapid determination of nitrite by reversed-phase high-performance liquid chromatography with fluorescence detection. J. Chromatogr. B Biomed. Sci. Appl. 2000, 746, 199-207. [CrossRef]

20. Jedličková, V.; Paluch, Z.; Alušík, Š. Determination of nitrate and nitrite by high-performance liquid chromatography in human plasma. J. Chromatogr. B 2002, 780, 193-197. [CrossRef]

21. Helaleh, M.I.; Korenaga, T. Ion chromatographic method for simultaneous determination of nitrate and nitrite in human saliva. J. Chromatogr. B Biomed. Sci. Appl. 2000, 744, 433-437. [CrossRef]

22. Niedzielski, P.; Kurzyca, I.; Siepak, J. A new tool for inorganic nitrogen speciation study: Simultaneous determination of ammonium ion, nitrite and nitrate by ion chromatography with post-column ammonium derivatization by Nessler reagent and diode-array detection in rain water samples. Anal. Chim. Acta 2006, 577, 220-224. [CrossRef] [PubMed]

23. Kage, S.; Kudo, K.; Ikeda, N. Simultaneous determination of nitrate and nitrite in human plasma by gas chromatography-mass spectrometry. J. Anal. Toxicol. 2002, 26, 320-324. [CrossRef] [PubMed]

24. Helmke, S.M.; Duncan, M.W. Measurement of the NO metabolites, nitrite and nitrate, in human biological fluids by GC-MS. J. Chromatogr. B 2007, 851, 83-92. [CrossRef] [PubMed]

25. Stobiecka, M.; Hepel, M.; Radecki, J. Transient conformation changes of albumin adsorbed on gold piezoelectrodes. Electrochim. Acta 2005, 50, 4873-4887. [CrossRef]

26. Welch, C.M.; Compton, R.G. The use of nanoparticles in electroanalysis: A review. Anal. Bioanal. Chem. 2006, 384, 601-619. [CrossRef]

27. Zhu, N.; Xu, Q.; Li, S.; Gao, H. Electrochemical determination of nitrite based on poly (amidoamine) dendrimer-modified carbon nanotubes for nitrite oxidation. Electrochem. Commun. 2009, 11, 2308-2311. [CrossRef]

28. Xue, W.; Hui, L.; Min, W.; Shu-Li, G.; Yan, Z.; Qing-Jiang, W.; Ping-Gang, H.; Yu-Zhi, F. Simultaneous electrochemical determination of sulphite and nitrite by a gold nanoparticle/graphene-chitosan modified electrode. Chin. J. Anal. Chem. 2013, 41, 1232-1237.

29. Dong, Q.; Huang, Y.; Song, D.; Wu, H.; Cao, F.; Lei, Y. Dual functional rhodium oxide nanocorals enabled sensor for both non-enzymatic glucose and solid-state pH sensing. Biosens. Bioelectron. 2018, 112, 136-142. [CrossRef]

30. Dong, Q.; Song, D.; Huang, Y.; Xu, Z.; Chapman, J.H.; Willis, W.S.; Li, B.; Lei, Y. High-temperature annealing enabled iridium oxide nanofibers for both non-enzymatic glucose and solid-state $\mathrm{pH}$ sensing. Electrochim. Acta 2018, 281, 117-126. [CrossRef]

31. Mubarak, A.T.; Mohamed, A.A.; Fawy, K.F.; Al-Shihry, A.S. A novel kinetic determination of nitrite based on the perphenazine-bromate redox reaction. Microchim. Acta 2007, 157, 99-105. [CrossRef]

32. Ensafi, A.A.; Amini, M. A highly selective optical sensor for catalytic determination of ultra-trace amounts of nitrite in water and foods based on brilliant cresyl blue as a sensing reagent. Sens. Actuators B Chem. 2010, 147, 61-66. [CrossRef]

33. Lo, H.S.; Lo, K.W.; Yeung, C.F.; Wong, C.Y. Rapid visual and spectrophotometric nitrite detection by cyclometalated ruthenium complex. Anal. Chim. Acta 2017, 990, 135-140. [CrossRef] [PubMed]

34. Ye, Y.; Guo, Y.; Yue, Y.; Zhang, Y. Facile colorimetric detection of nitrite based on anti-aggregation of gold nanoparticles. Anal. Methods 2015, 7, 4090-4096. [CrossRef]

35. Zhang, X.X.; Song, Y.Z.; Fang, F.; Wu, Z.Y. Sensitive paper-based analytical device for fast colorimetric detection of nitrite with smartphone. Anal. Bioanal. Chem. 2018, 410, 2665-2669. [CrossRef] [PubMed]

36. Ghasemi, J.; Jabbari, A.; Amini, A.; Oskoei, A.; Abdolahi, B. Kinetic spectrophotometric determination of nitrite based on its catalytic effect on the oxidation of methyl red by bromate. Anal. Lett. 2004, 37, 2205-2214. [CrossRef]

37. Moldovan, Z. Kinetic spectrophotometric determination of nitrite with Tropaeolin 00-Bromate System. Anal. Lett. 2010, 43, 1344-1354. [CrossRef]

38. Moorcroft, M.J.; Davis, J.; Compton, R.G. Detection and determination of nitrate and nitrite: A review. Talanta 2001, 54, 785-803. [CrossRef]

39. Shinn, M.B. Colorimetric method for determination of nitrate. Ind. Eng. Chem. Anal. Ed. 1941, 13, 33-35. [CrossRef] 
40. Afkhami, A.; Masahi, S.; Bahram, M. Spectrophotometric determination of nitrite based on its reaction with p-nitroaniline in the presence of diphenylamine in micellar media. Bull. Korean Chem. Soc. 2004, 25, 1009-1011.

41. Cherian, T.; Narayana, B. A new system for the spectrophotometric determination of trace amounts of nitrite in environmental samples. J. Braz. Chem. Soc. 2006, 17, 577-581. [CrossRef]

42. Noor, N.S.M.; Tan, L.L.; Heng, L.Y.; Chong, K.F.; Tajuddin, S.N. Acrylic microspheres-based optosensor for visual detection of nitrite. Food Chem. 2016, 207, 132-138. [CrossRef] [PubMed]

43. Chen, J.; Pang, S.; He, L.; Nugen, S.R. Highly sensitive and selective detection of nitrite ions using Fe3O4@SiO2/Au magnetic nanoparticles by surface-enhanced Raman spectroscopy. Biosens. Bioelectron. 2016, 85, 726-733. [CrossRef] [PubMed]

44. Tsikas, D. Analysis of nitrite and nitrate in biological fluids by assays based on the Griess reaction: Appraisal of the Griess reaction in the L-arginine/nitric oxide area of research. J. Chromatogr. B 2007, 851, 51-70. [CrossRef] [PubMed]

(C) 2020 by the authors. Licensee MDPI, Basel, Switzerland. This article is an open access article distributed under the terms and conditions of the Creative Commons Attribution (CC BY) license (http://creativecommons.org/licenses/by/4.0/). 